\title{
A Nd:YAG laser in the treatment of vascular malformations of the skin in a patient with blue rubber bleb nevus syndrome
}

\author{
Jacek T. Szymańczyk ${ }^{1}$, Agnieszka Gradzińska ${ }^{1}$, Janusz J. Szymańczyk ${ }^{2}$ \\ 'Department of Dermatology, Medical University of Warsaw, Warsaw, Poland \\ 2Department of Dermatology and Venerelogy, Medical University of Lodz, Lodz, Poland
}

Adv Dermatol Allergol 2021; XXXVIII (2): 327-330 DOI: https://doi.org/10.5114/ada.2021.106211

Blue rubber bleb nevus syndrome (BRBNS) is a rare congenital disorder characterized by vascular malformations on the skin and frequently in the gastrointestinal (GI) system, but they may affect other organs as well. Lesions in the Gl system often lead to bleeding and subsequent anaemia [1, 2]. In 1860 Gascoyen was the first to report the association between $\mathrm{Gl}$ and skin lesions [3], and in 1958 William B. Bean presented a similar case and coined the term "blue rubber bleb nevus syndrome" [4]. To date, over 200 cases of BRBNS have been reported. Cases of BRBNS are found in all races, but it is mostly observed in Caucasians. It affects both sexes equally. Most of BRBNS appear to be sporadic, with few cases showing congenital autosomal dominant inheritance and the recently discovered relationship with somatic mutations in the gene encoding TIE $_{2}$ (TEK) [5]. BRBNS may be present at birth or develop in childhood, with possible later complications, e.g. GI haemorrhage and orthopaedic abnormalities [6].

We report a case of a 45 -year-old woman with numerous, diffuse vascular nodules on her trunk, extremities, and on the mucosal membrane. All lesions were blue with diameters ranging from 5 to $38 \mathrm{~mm}$ (Figure 1). Upon physical examination, all lesions were soft and easily compressible, but after removing the pressure they rapidly filled back to their previous shape.

Vascular lesions had been present since early childhood and had grown in number until puberty. During her childhood the patient underwent many operations (Figure 2). Mainly large lesions, which were disfiguring her face or those located in the groin and extremities and had the biggest potential of bleeding after trauma, were referred for surgery. But in case of numerous nod- ules, diffused all over the skin surface, surgical excision of all lesions would be impossible due to technical limitations. Our patient was hospitalized many times due to recurrent anaemia. There were never episodes of serious bleeding from the GI tuck. In ultrasound examinations as well as in computed tomography, in the left liver lobe there was a cystic lesion with septations without visible flow, measuring $90 \times 95 \times 130 \mathrm{~mm}$. The remaining liver parenchyma was without lesions and with normal echotexture (Figure 3).

The patient was offered treatment for existing skin lesions using a neodymium-doped yttrium aluminium garnet (Nd:YAG) laser. The Nd:YAG laser is a device that emits light with the wavelength of $1064 \mathrm{~nm}$. Laser light is invisible to the human eye and is transmitted by a flex-

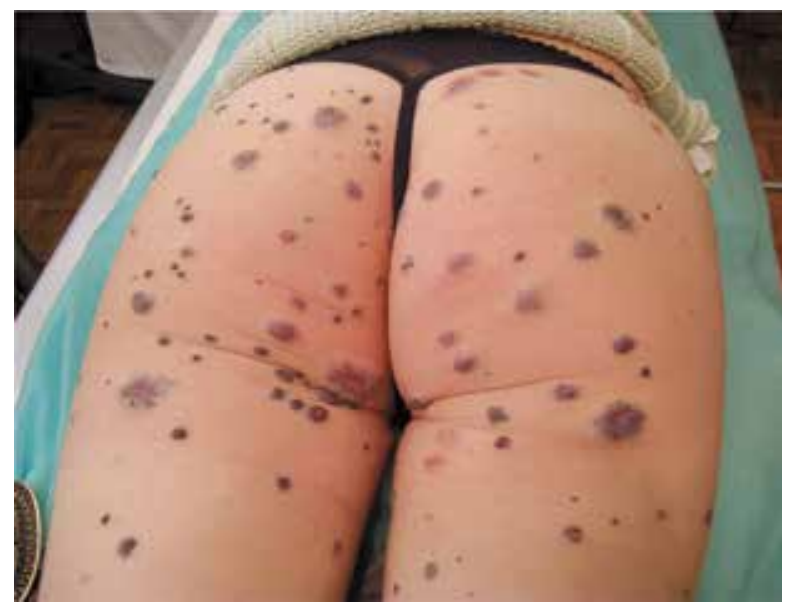

Figure 1. Vascular malformations within the skin of a patient with BRBNS

Address for correspondence: Jacek T. Szymańczyk MD, Department of Dermatology, Medical University of Warsaw, Warsaw, Poland, e-mail: szymanczyk.jacek@gmail.com Received: 30.08.2019, accepted: 23.11.2019. 


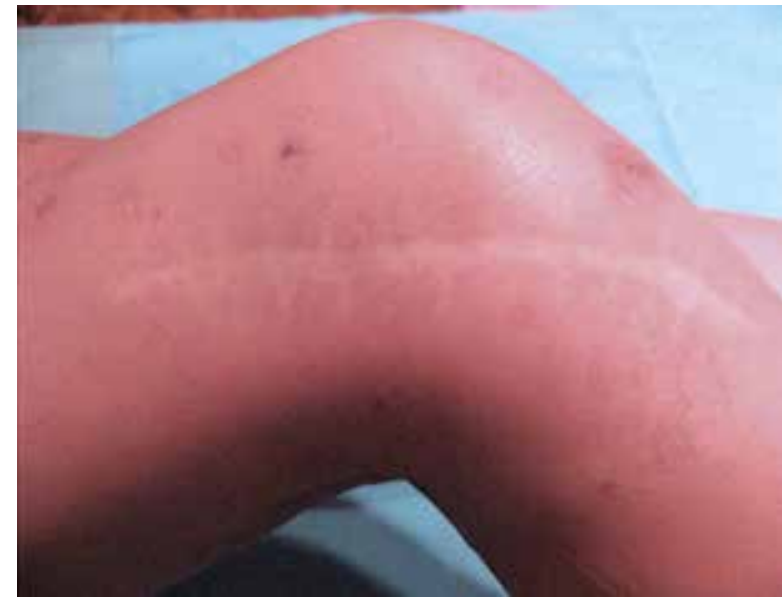

Figure 2. Scar within the knee after surgical excision of a large vascular lesion

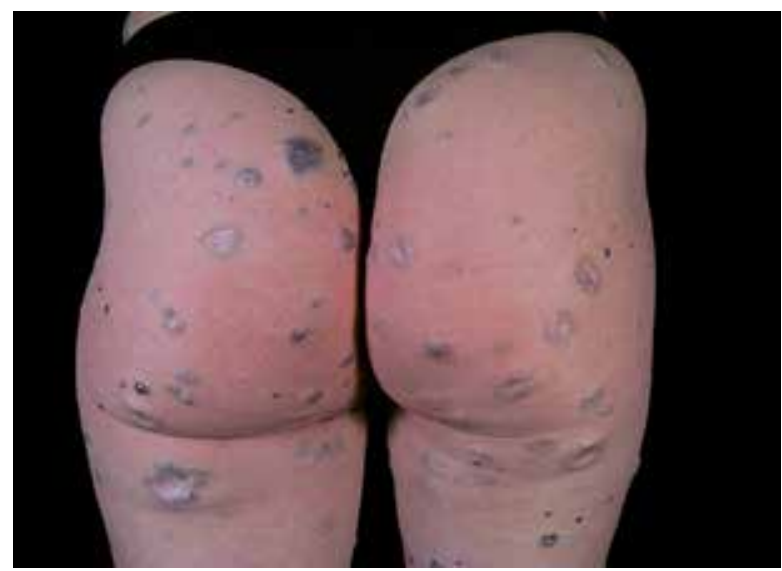

Figure 4. Scars 3 months after Nd:YAG laser irradiation

ible optical fibre with a core diameter of 400 to $800 \mathrm{~nm}$ with various treatment tips. The depth of laser penetration is up to $6 \mathrm{~mm}$, and it has an affinity to protein [7]. Due to such high penetration, this type of laser is used to coagulate deep cavernous haemangiomas, skin tumours, or lesions caused by HPV infection (Condylomas a accuminata, Bovenoid papulosis) [8]. Because procedures with photocoagulations are painful, we conducted the treatment under local anaesthesia with $1 \%$ lignocaine as a non-contact procedure (from a distance) to avoid potential perforation of the skin lesions and uncontrolled bleeding. We used a continuous light mode. The time of the treatment depended on the size of the skin lesions and varied from 3 to $30 \mathrm{~s}$. The expected final effect of the treatment was total flattening of the nodule (to the healthy skin level). The laser treatment of vascular malformation was conducted through the dermis layer of the skin, so we had to reckon with the risk of scarring within the treated area. We found that the healing process and scarring consisted of 2 main phases. In the

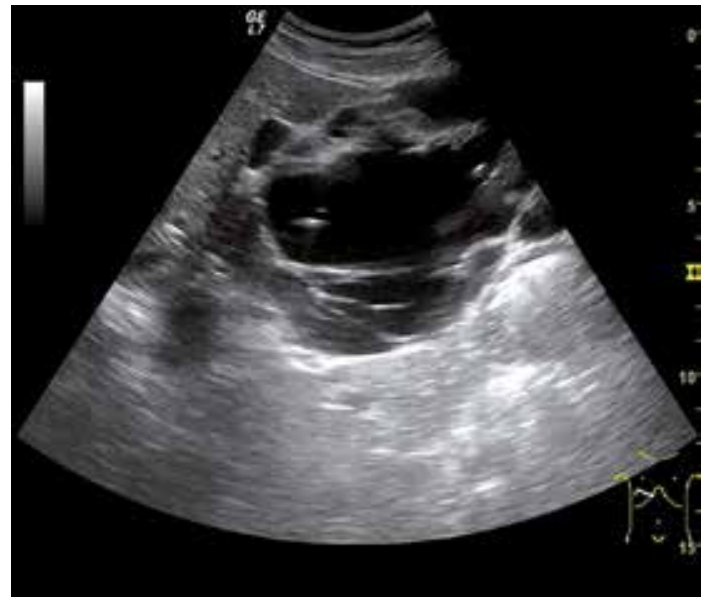

Figure 3. Picture from liver ultrasound examination in a patient with BRBNS

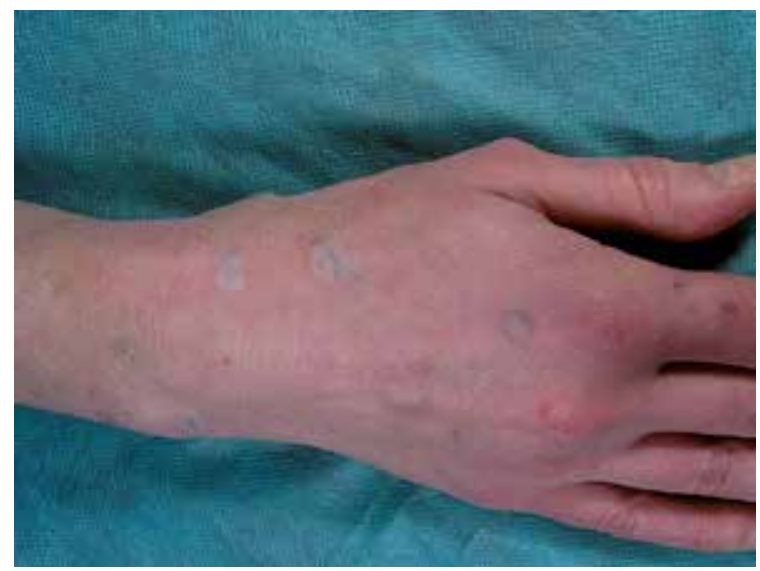

Figure 5. The scars 1 year after laser treatment

first period (about 3 months after radiation) the scar was quite visible with hyperpigmentation (Figure 4). In the later healing phase, the scar was steadily decolouring until becoming close to the regular skin colour (Figure 5). Small lesions 1-5 $\mathrm{mm}$ in diameter required only one laser treatment. Those larger in diameter (15-30 mm) needed more treatments until total flattening to the level of the surrounding healthy skin. Using non-contact radiation mode, we avoided complications such as bleeding or perforation. The final cosmetical effect was satisfying for both patient and physician.

BRBNS is a rare disorder with characteristic vascular malformations of the skin and GI truck [9]. To date, over 200 cases of BRBNS have been reported. Aside from lesions in the Gl system, typical malformations have been found in nasopharynx, oral cavity, spleen, liver, peritoneum, pleura, urinary bladder, parotid gland, eye and orbital cavity, and central nervous system [6, 10-17]. Iron deficiency anaemia due to bleeding from the GI truck is an often associated finding in patients with BRBNS [13, 
18-20]. Patients with anaemia require iron supplementation and sometimes even blood transfusion [14]. Also, thrombocytopaenia and chronic consumption coagulopathy have been described [21-23]. Patients with BRBNS may also suffer from orthopaedic problems [24]. The pressure of haemangiomas that are adjacent to bones may cause bone atrophy. Conversely, hypertrophy caused by hypervascularity can be also present. Both lead to pathologic fractures and skeletal bowing $[1,24]$.

There are 3 main types of cutaneous lesions in BRBNS [4]. Type I: blue, rubbery, blood-filled sacs with a smooth surface and thin wall, which are easily compressible and refill when pressure is removed. Those are the most characteristic cutaneous lesions for BRBNS. They are mainly asymptomatic, but sometimes they may be painful [13, 19, 25-27]. Type II are large, cavernous lesions that may compress vital structures. Type III are irregular, blue-black macules or papules, which rarely blanche after pressure [20]. The lesions in BRBNS may appear at birth or in early childhood, and their size varies from $1 \mathrm{~mm}$ to $10 \mathrm{~cm}$ in diameter. The size and number of lesions tend to increase with age $[26,27]$. Those lesions do not have a tendency for spontaneous bleeding or malignant transformation [26, 28].

There is no standard of care or systemic treatment for BRBNS. Surgical treatment of cutaneous lesions is used mainly for large lesions, those that cause pressure to bones, or those that cause other dysfunctions. Small malformations are considered cosmetic problem and are often not treated. The use of a carbon dioxide laser in the treatment of lesions in BRBNS has been reported [29], but this wavelength is not recommended for vascular lesions. Experience with endoscopic sclerotherapy suggests that it is rather ineffective and may lead to ulcerations and strictures. Cases of endoscopic $\mathrm{Nd}$ :YAG photocoagulation of vascular malformations in GI truck have been reported [30].

The preferred treatment of cutaneous lesions is the use of a ruby, argon, or carbon dioxide laser, although the wavelength of the latter does not seem to be accurate. The best cosmetic effects were achieved with a pulse dye laser and long-pulsed Nd:YAG laser [29, 31]. The cosmetic effects of treatment of skin lesions in BRBN syndrome using the long-pulsed Nd:YAG laser [31] are very similar and comparable with the results obtained by us using the $\mathrm{Nd}$ :YAG laser with continuous light mode.

Clinically, the differential diagnosis for BRBNS should include hereditary haemorrhagic telangiectasia (RendouOsler-Weber syndrome) in which diffuse telangiectasia and large arteriovenous malformations are present on the skin. Up to one-third of patients have similar malformations in respiratory or GI truck [27, 32]. BNBRS must be differentiated from Maffuccini syndrome, characterized by diffuse vascular malformations in the skin and soft tissues, which is associated with bone malformations and risk of malignant transformation [33]. Kippel-
Trenaunay-Weber syndrome with varicosities, bone and soft tissue and skin lesions located on one extremity is another condition to be considered in differential diagnosis [34].

There are not many reports of systemic treatment in BRBNS. Systemic steroids and interferon $\alpha$ result in partial remission of skin and Gl lesions during treatment. Soon after discontinuation of the treatment all the lesions are likely to recrudesce $[35,36]$.

Based on abovementioned information, we think that treatment of skin lesions with a Nd:YAG laser is a very encouraging and promising alternative to the previously used methods.

\section{Conflict of interest}

The authors declare no conflict of interest.

\section{References}

1. Moodley M, Ramdial P. Blue rubber bleb nevus syndrome: case report and review of the literature. Peduatrics 1993; 92: 160-2.

2. Rabinowitz LG, Esterly NB. Blue rubber bleb nevus syndrome. In: Pediatric Dermatology. Schachner LA, Hansen RC (eds.) $2^{\text {nd }}$ ed. Churchill Livingstone, New York 1995; 969-70.

3. Romão Z, Pontes J, Lopes $\mathrm{H}$, et al. Endosonography in the diagnosis of "blue rubber bleb nevus syndrome": an uncommon cause of gastrointestinal tract bleeding. I Clin Gastroenterol 1999; 28: 262-5.

4. Bean WB. Vascular spiders and related lesions of the skin. Springfield (IL), Thomas 1958.

5. Soblet J, Kangas J, Nätynki M, et al. Blue rubber bleb nevus (BRBN) syndrome is caused by somatic TEK (TIE2) mutations. I Invest Dermatol 2017; 137: 207-16.

6. Hoenig JH, Umlas J, Woog JJ, et al. Orbital lesions in the blue rubber bleb nevus syndrome. Ophthalmology 1996; 102: 933-6.

7. Landthaler M. Der Neodym-YAG-Laser in der Dermatologie. Munch Med Wsch1984; 126: 1108-12.

8. Apfelberg DB, Maser MR, White DN, Lash H. A preliminary study of the combined effect in neodymium: YAG laser photocoagulation and direct steroid instillation in the treatment of capillary cavernous hemangiomas of infancy. Ann Plast Surg 1983; 22: 94-104

9. Nahm WK, Moise S, Eichenfield LF, et al. Venous malformations in blue rubber bleb nevus syndrome: variable onset of presentation. J Am Acad Dermatol 2004; 50 (5 Suppl): S101-6.

10. Chang EL, Rubin PA. Bilateral multifocal hemangiomas of the orbit in the blue rubber bleb nevus syndrome. Ophthalmology 2002; 109: 537-41.

11. Kim SJ. Blue rubber bleb nevus syndrome with central nervous system involvement. Pediatr Neurol 2000; 22: 410-2.

12. McCannel CA, Hoenig J, Umlas J, et al. Orbital lesions in the blue rubber bleb nevus syndrome. Ophthalmology 1996; 103: 933-6.

13. McKinlay JR, Kaiser J, Barrett TL, Graham B. Blue rubber bleb nevus syndrome. Cutis 1998; 62: 97-8.

14. Paulas S, Baack B, Lavisonn D. Tender bluisch papules on the trunk and extremities. Arch Dermatol 1992; 129: 1505-10. 
15. Satya-Murti S, Navada S, Eames F. Central nervous system involvement in blue-rubber-bleb-nevus syndrome. Arch Neurol 1986; 10: 686-8.

16. Sobottka Ventura AC, Remonda L, Mojon DS. Intermittent visual loss and exophthalmos due to the Blue rubber bleb nevus syndrome. Am J Ophthalmol 2001; 132: 132-5.

17. Walshe MM, Evans CD, Warin RP. Blue rubber bleb naeus. Br Med J 1966; 2: 931-2.

18. Apak H, Celkan T, Ozkan A, et al. Blue rubber bleb nevus syndrome associated with consumption coagulopathy: treatment with interferon. Dermatology 2004; 208: 345-8.

19. Carr MM, Jamieson CG, Lal G. Blue rubber bleb nevus syndrome. Can J Surg 1996; 39: 59-62.

20. Oranje AP. Blue rubber bleb nevus syndrome. Pediatr Dermatol 1986; 3: 304-10.

21. Fretzin DF, Potter B. Blue rubber bleb nevus. Arch Intern Med 1965; 116: 924-9.

22. Hofhuis WJD, Orange AP, Bouquet J, Sinaasappel M. Blue rubber-bleb nevus syndrome: report of a case with consumption coagulopathy complicated by manifest thrombosis. Eur J Pediatr 1990; 149: 526-8.

23. Lichtig C, Alroy G, Gellei B, Valero A. Multiple skin and gastro-intestinal haemangiomata (blue rubber-bleb nevus): report of case with thrombocytopenia, hypercalcemia and coinciding cystic cell carcinoma. Dermatologica 1971; 142: 356-62.

24. McCarthy JC, Goldberg MJ, Zimbler S. Orthopaedic dysfunction in the blue rubber-bleb nevus syndrome. J Bone Joint Surg Am 1982; 64: 280-3.

25. Bonde CT, Jakobsen E, Hasselbalch HC. "Blue rubber bleb nevus syndrome” - or Bean's syndrome. Ugeskr Laeger 1997; 159: 4274-5.

26. Crepeau J, Poliquin J. The blue rubber bleb nevus syndrome. J Otolaryngol 1981; 10: 387-90.

27. McCauley RG, Leonidas JC, Bartoshesky LE. Blue rubber bleb nevus syndrome. Radiology 1979; 133: 375-7.

28. Gallo SH, McClave SA. Blue rubber bleb nevus syndrome: gastrointestinal involvement and its endoscopic presentation. Gastrointest Endosc 1992; 38: 72-6.

29. Olsen TG, Milroy SK, Goldman L, Fidler JP. Laser surgery for blue rubber bleb nevus. Arch Dermatol 1979; 115: 81-2.

30. Morris L, Lynch PM, Gleason WA Jr, et al. Blue rubber bleb nevus syndrome: laser photocoagulation of colonic hemangiomas in a child with microcytic anemia. Pediatr Dermatol 1992; 9: 91-4.

31. Moser CM, Hamsch C. Successful treatment of cutaneous venous malformations in a patient with blue rubber bleb naevus syndrome by Nd:YAG laser. Br I Dermatol 2012; 166: 1143-5.

32. Paller AS. Vascular disorders. Dermatol Clin 1987; 5: 239-50.

33. Goraya JS, Marwaha RK, Vatve M, Trehan A. Blue rubber bleb nevus syndrome: a cause for reccurent episodic severe anema. Pediatr Hematol Oncol 1998; 48: 273-7.

34. Arguedas MR, Shore G, Wilcox CM. Congenital vascular lesions of the gastrointestinal tract: blue rubber bleb nevus and Klippel-Trenaunay syndromes. South Med J 2001; 94: 405-10.

35. Dieckmann K, Maurage C, Faure N, et al. Combined lasersteroid therapy in blue rubber bleb nevus syndrome: case report and review of the literature. Eur J Pediatr Surg 1994; 4: 372-4.

36. Yacoub M, Gnaoui A, Abroug S, et al. The "blue rubber bleb nevus" (Bean's syndrome): uncommon cause of gastrointestinal bleeding. Ann Pediatr 1993; 40: 157-61. 